\title{
Effect of diet composition and incubation time on feed indigestible neutral detergent fiber concentration in dairy cows
}

\author{
S. J. Krizsan ${ }^{1}$ and P. Huhtanen \\ Swedish University of Agricultural Sciences, Department of Agricultural Research for Northern Sweden, S-901 83 Umeå, Sweden
}

\begin{abstract}
Indigestible neutral detergent fiber (NDF) predicts forage digestibility accurately and precisely when determined by a 288 -h ruminal in situ incubation, and it is an important parameter in mechanistic rumen models. The long incubation time required is a disadvantage. Further, intrinsic cell wall characteristics of feeds should be determined under ideal conditions for fiber digestion. The objective of this study was to determine the effects of diet composition and rumen incubation time on the concentrations of indigestible NDF (iNDF) for a wide range of feeds in dairy cows. Additionally, predicted concentrations of unavailable NDF generated using the National Research Council (NRC) model and the Cornell Net Carbohydrate and Protein System (CNCPS) were evaluated. Indigestible NDF was evaluated in 18 feeds using 4 cows in a splitsplit plot design. Treatments were in a $3 \times 3$ factorial arrangement, consisting of different diets and incubation times. Diet composition was primarily varied by changing the level of concentrate supplementation between 190 (low), 421 (medium), and 625 (high) g/kg of diet dry matter (DM). Grass silage was used as the basal forage for all cows. The feeds were incubated for 144, 216, and $288 \mathrm{~h}$. Indigestible NDF was determined from 2-g samples weighed into polyester bags with a pore size of $12 \mu \mathrm{m}$ and a pore area equal to $6 \%$ of the total surface area, giving a sample size to surface ratio of $10 \mathrm{mg} / \mathrm{cm}^{2}$. Across all feeds, the measured iNDF concentrations ranged from 6 to $516 \mathrm{~g} / \mathrm{kg}$ of DM. The feed iNDF concentration was not affected by the cow used, but diet composition had a significant effect. The mean measured iNDF concentrations for cows consuming low-, medium-, and high-concentrate diets were 178,186 , and $197 \mathrm{~g} / \mathrm{kg}$ of DM, respectively. The incubation time also affected the feed iNDF concentrations, which averaged 199, 185, and $177 \mathrm{~g} / \mathrm{kg}$ of DM for 144-, 216-, and 288-h incubations, respectively. We also observed significant interactions between incubation
\end{abstract}

Received May 20, 2012.

Accepted November 16, 2012

${ }^{1}$ Corresponding author: sophie.krizsan@slu.se time and feed, and between diet composition and feed, with fiber-rich feeds being most sensitive to these factors. The evaluation of model predictions of unavailable NDF indicated poor precision with prediction errors of 56 (NRC) and 84 (CNCPS) g/ kg of DM. Indigestible NDF should be determined based on 288-h ruminal in situ incubations in cows consuming diets with a low proportion of concentrate to represent the feed fraction that is unavailable to the animal.

Key words: concentrate level, dairy cow, in situ, indigestible neutral detergent fiber

\section{INTRODUCTION}

Ruminant animals can utilize fibrous plant material efficiently because their digestive system is based on microbial degradation in the forestomachs and the mechanism of selective retention of feed particles in the rumen. The potential of ruminants to digest the cell walls of plant material has been defined from the fraction of NDF that is not digested by the anaerobic rumen microbes given indefinite rumen residence; that is, the material that cannot be broken down by the ruminal microbiota even after an infinite period. The determination of the indigestible cell wall fraction is critical when describing digestion kinetics. This fraction is called indigestible NDF (iNDF) and describes the intrinsic properties of a plant's cell walls (Mertens, 1993). However, it is not known whether extrinsic factors such as the diet composition of the animal will influence iNDF concentration.

Concentration of iNDF accurately and precisely predicted forage OM digestibility when determined from a 288-h ruminal in situ incubation (Nousiainen et al., 2003). Moreover, the relationship between iNDF and forage OM digestibility was more consistent than those for other in vitro methods in predictions of OM digestibility (Huhtanen et al., 2006; Krizsan et al., 2012b). A rapid and cost-effective method for iNDF analysis by commercial laboratories has been developed from calibration of near infrared reflectance spectroscopy (NIRS; Nousiainen et al., 2004); NIRS is now routinely applied in iNDF analyses of farm samples in all Nordic countries. Indigestible NDF is, by definition, an 
ideal nutritional entity (Van Soest, 1994) because its digestibility is zero across a wide range of feedstuffs. Therefore, it has been used as an internal marker when measuring total-tract digestibility (Huhtanen et al., 1994), in estimates of rumen outflow (Ahvenjärvi et al., 2000), and as a marker for evaluating the rate of passage in rumen evacuation studies (Krizsan et al., 2010). Indigestible NDF is also an important parameter in dynamic rumen models (Danfær et al., 2006).

Despite the wide application of iNDF, few documented recommendations of the method exist. In situ and in vitro laboratory methods should ideally be calibrated against in vivo digestibility data. The long incubation time in situ required in the determination of iNDF is a disadvantage. Moreover, the intrinsic cell wall properties of feeds should be determined under ideal conditions for fiber digestion. The objective of this study was to determine the effects of diet composition and rumen incubation time on the concentrations of iNDF for a wide range of feeds in dairy cows. Additionally, predicted concentrations of unavailable NDF generated using the National Research Council model (NRC, 2001) and the Cornell Net Carbohydrate and Protein System (CNCPS; Fox et al., 2004) were evaluated.

\section{MATERIALS AND METHODS}

\section{Experimental Design, Cows, and Diets}

The animals used in this experiment were registered and cared for according to guidelines approved by the University Animal Care and Use Committee, and the experiment was carried out in accordance with the laws and regulations controlling experiments performed with live animals in Sweden. The effects of the proportion of concentrate in the diet (low, medium, and high) and incubation time $(144,216$, and $288 \mathrm{~h})$ on the concentrations of iNDF were evaluated for 18 feeds (10 classified as concentrate ingredients and 8 as forages) using 4 ruminally cannulated cows in a split-split plot design. Cow within period was the main plot observation, incubation time within cow and period was the sub plot, and feed within time, cow, and period was the sub-sub plot. Two cows were used on each occasion, over a total of 6 ruminal in situ incubations. Four in situ incubations were conducted with lactating cows averaging (SD) 92 (22.5) DIM at the start of the incubations, and 2 incubations were conducted with dry cows. Average BW (SD) for all cows, and milk production (SD) for the lactating cows at the start of the incubations were $585(70) \mathrm{kg}$, and 31 (6.5) $\mathrm{kg}$ of milk, respectively. The diets and incubation times were organized in a $3 \times 3$ factorial arrangement.
Diet composition was primarily varied by changing the concentrate proportion, aiming at low, medium, and high inclusions of 200,400, and $600 \mathrm{~g} / \mathrm{kg}$ of diet DM. Grass silage was used as the basal forage for all cows during the incubations. The lactating cows were kept in a loose house system and offered TMR ad libitum in Roughage Intake Control feeders (Insentec B.V., Marknesse, the Netherlands), and their intake was recorded individually at each visit. The lactating cows were provided feed on 6 occasions daily as follows: 0400, 0700, 1000, 1300, 1600, and $1900 \mathrm{~h}$. The TMR consisted of grass silage, crimped barley, and canola meal (ExPro, Lantmännen Lantbruk AB, Stockholm, Sweden) and were supplemented with a commercial concentrate (Solid 220; Lantmännen Lantbruk AB) provided in separate concentrate feeders (Cablevey Feeding Systems, Intraco Inc., Oskaloosa, IA). Crimped barley was ensiled using propionic acid (Perstorp AB, Perstorp, Sweden) applied at a rate of approximately 4 $\mathrm{L} / \mathrm{t}$, holding an average DM of $72 \%$. The dry cows were kept in a pen that housed 11 cows in total and were group-fed to provide 5 to $6 \mathrm{~kg}$ of grass silage DM per animal and day. Additionally, the dry cows were fed 1 $\mathrm{kg}$ of the same commercial concentrate as the lactating cows on an air-dry basis in separate concentrate feeders. The restricted feeding of silage of the dry cows resulted in the lowest level of concentrate supplementation. Assuming an average value of $5.5 \mathrm{~kg} / \mathrm{d}$ in silage DMI, the maximum proportion of concentrate would be $190 \mathrm{~g} /$ $\mathrm{kg}$ with a CV of $15 \%$ and 2 standard deviation units range in silage DMI. Composite samples of each dietary ingredient were made from 3 samplings during each of the 6 incubations. Feed samples were dried at $60^{\circ} \mathrm{C}$ for $48 \mathrm{~h}$ and ground through a 1.0-mm screen before chemical analysis. The proportion of dietary DM from each ingredient was calculated from the average DM determined for the 3 weekly samplings of feed samples after drying at $60^{\circ} \mathrm{C}$ for $48 \mathrm{~h}$, and from observed or estimated total feed intake. The composition of each diet was calculated from the chemical composition of the dietary ingredients and the proportion of dietary DM contributed by each ingredient.

\section{In Situ Incubations and Rumen Fluid Sampling}

The iNDF concentration of each feed sample was determined following in situ incubations of 144, 216, and $288 \mathrm{~h}$ in the rumen using 2 cows at each occasion. Samples of $2 \mathrm{~g}$ were weighed into polyester bags with a pore size of $12 \mu \mathrm{m}$ and a pore area equal to $6 \%$ of the total surface area (Saatifil PES 12/6, Saatitech S.p.A., Veniano, Italy). The internal dimensions of the nylon bags and the sample size were adjusted to give a 
sample size to surface area ratio of $10 \mathrm{mg} / \mathrm{cm}^{2}$. After their removal from the rumen, the bags were rinsed in a household washing machine (using the rinsing part of the wool wash cycle; Electrolux Wascator W75MP, AB Electrolux, Stockholm, Sweden), boiled for $1 \mathrm{~h}$ in neutral detergent solution including sodium sulfite (100 mL/g of sample; Mertens et al., 2002), thoroughly rinsed, dried at $60^{\circ} \mathrm{C}$ for $24 \mathrm{~h}$, and weighed. Indigestible NDF was expressed exclusive of residual ash.

Samples of rumen fluid were collected on 5 sampling occasions during $1 \mathrm{~d}$ of the $12-\mathrm{d}$ period in each of the incubations. Rumen fluid was taken from 3 locations in the mid-ventral sac of the rumen of each cow. Samples were transferred to a thermos flask using a metal filter probe connected to a light vacuum at 0 (just before feeding), 2, 4, 6 , and $8 \mathrm{~h}$ after feeding. The $\mathrm{pH}$ of the samples was measured immediately after collection; thereafter, $45 \mathrm{~mL}$ of each sample was stored at $-20^{\circ} \mathrm{C}$. Ruminal fluid samples were later thawed, composited on volume basis within day, and analyzed for VFA using a Waters Alliance 2795 HPLC system with Waters 2414 RI detector (Waters Corp., Milford, MA) as described by Ericson and André (2010), and $\mathrm{NH}_{3}$ according to Broderick and Kang (1980) on an AutoAnalyzer 3 (SEAL Analytical, Mequon, WI).

\section{Feed Samples and Chemical Analysis}

Samples of barley (Hordeum vulgare), oat (Avena sativa), soybean (Glycine max) meal, canola (Brassica napus) meal, palm kernel (Elaeis oleifera) cake, and wheat (Triticum aestivum) bran were provided by the feed manufacturer AB Västerbottens Fodercentral (Umeå, Sweden). Samples of dried alfalfa (Medicago sativa) and sugar beet (Beta vulgaris) pulp shreds enriched with molasses were taken from bags of the commercial feeds Krafft Lusern (Krafft AB, Falkenberg, Sweden) and Betfor (Nordic Sugar A/S, Copenhagen, Denmark). Samples taken from 2 grass silages that were harvested on June 12 and 26, 2008, from a timothy (Phleum pratense)-dominated sward at Röbäcksdalen Research Farm in Umeå $\left(63^{\circ} 45^{\prime} \mathrm{N}, 20^{\circ} 17^{\prime} \mathrm{E}\right)$ were included in this experiment. Samples of barley straw and hempseed (Cannabis sativa) cake were also from feeds harvested at Röbäcksdalen Research Farm. A hay sample from a timothy-dominated sward harvested in July 2010 was included in the study. Samples of corn silage (Zea mays) and whole-crop barley silage that have been used as experimental feeds in dairy cow feeding studies in Sweden and Finland were also included. Samples of the industrial byproducts (barley hulls and barley fiber) from an integrated starch ethanol process were provided by Altia Plc (Helsinki, Finland). A sample of birch (Betula pubescens) twigs, a common feed for ruminant browsers, was also incubated in situ to determine its concentration of iNDF. All feed samples were dried at $60^{\circ} \mathrm{C}$ for $48 \mathrm{~h}$ and were ground through a $2.0-\mathrm{mm}$ screen for in situ incubations or a 1.0-mm screen for chemical analysis, using the same cutting mill (Retsch SM 2000, Retsch GmbH, Haan, Germany).

Residual moisture of all feed samples was determined by oven drying for $16 \mathrm{~h}$ at $105^{\circ} \mathrm{C}$. Ash concentration was determined by ignition of the dried sample at $500^{\circ} \mathrm{C}$ for $4 \mathrm{~h}$. The samples were analyzed for NDF using heatstable $\alpha$-amylase (Mertens et al., 2002) in an Ankom ${ }^{200}$ Fiber Analyzer (Ankom Technology Corp., Macedon, NY). Ash was determined in the bag residues and NDF was expressed free of residual ash. The lignin concentration of the feeds was determined by solubilization of cellulose in $12 \mathrm{M}$ sulfuric acid after extraction with acid detergent according to the procedure described by Gomes et al. (2011). The method was modified by using a glass microfiber filtering aid to trap small particles (934-AH, Whatman Inc., Piscataway, NJ) during the recovery of the insoluble residue in $100-\mathrm{mL}$ filter crucibles with a porosity of 40 to $100 \mu \mathrm{m}$ (Saveen \& Werner AB, Limhamn, Sweden) according to Raffrenato and Van Amburgh (2011). Nitrogen concentration was determined according to the Dumas method (method 968.06; AOAC International, 1998) using a Leco FP 428 nitrogen analyzer (Leco Corp., St Joseph, MI), and the $\mathrm{CP}$ value for each sample was calculated as $\mathrm{N} \times 6.25$. The concentration of NDIN was determined in NDF residues by the Kjeldahl method (Nordic Committee on Food Analysis, 1976) using a 2020 Digestor ( $\mathrm{Cu}$ used as a catalyst) and a 2400 Kjeltec Auto Analyzer Unit (Foss Analytical A/S, Hillerød, Denmark).

\section{Prediction Models of Unavailable NDF}

Unavailable NDF was calculated by subtracting available NDF according to NRC (2001; Eq. 1) from NDF excluding NDIN $\times 6.25($ NDICP), and according to Fox et al. (2004) in the CNCPS (Eq. 2):

$$
\begin{gathered}
\text { Available } \mathrm{NDF}_{\mathrm{NRC}}=(\mathrm{NDF}-\mathrm{NDICP}-\mathrm{ADL}) \\
\times\left\{1-[\mathrm{ADL} /(\mathrm{NDF}-\mathrm{NDICP})]^{0.667}\right\} \\
\text { Unavailable } \mathrm{NDF}_{\mathrm{CNCPS}}=\mathrm{ADL} \times 2.4
\end{gathered}
$$

where concentrations of NDICP, NDF, and ADL in Eq. [1] and [2] are given in percent of DM.

\section{Statistical Analysis}

All data were analyzed using the GLM procedure of SAS (release 9.2, 2002-2003; SAS Institute Inc., Cary, $\mathrm{NC)}$ by the following model: 


$$
\begin{aligned}
Y_{i j k}= & \mu+C_{i}+D_{j}+P(D)_{j k}+C_{i} \times D_{j} \times P(D)_{j k} \\
+ & T_{l}+D_{j} \times T_{l}+C_{i} \times D_{j} \times P(D)_{j k} \times T_{l} \\
& +F_{m}+D_{j} \times F_{m}+T_{l} \times F_{m}+e_{i j k l m},
\end{aligned}
$$

where $Y_{i j k}=$ dependent variable, $\mu=$ overall mean, $C_{i}$ $=$ effect of cow $i, D_{j}=$ effect of diet $j, P(D)_{j k}=$ effect of period $k$ within diet $j, C_{i} \times D_{j} \times P(D)_{j k}=3$-way interaction between cow $i$, diet $j$, and period $k$ within $\operatorname{diet} j$ (main plot error), $T_{l}=$ effect of incubation time $l, D_{j} \times$ $T_{l}=2$-way interaction between diet $j$ and incubation time $l, C_{i} \times D_{j} \times P(D)_{j k} \times T_{l}=4$-way interaction between cow $i$, diet $j$, period $k$ within diet $j$ and incubation time $l$ (sub plot error), $F_{m}=$ effect of feed $m, D_{j} \times$ $F_{m}=2$-way interaction between $\operatorname{diet} j$ and feed $m, T_{l} \times$ $F_{m}=2$-way interaction between incubation time $l$ and feed $m$, and $e_{i j k} \sim N\left(0, \sigma_{e}^{2}\right)$ is the random residual error. Rumen fluid data were analyzed using a model including the effects of cow and diet as described by the above model. Least squares means are reported and mean separation was done by least significant difference to test differences between treatments.

Prediction equations were evaluated by linear regression. The observed values (y) were plotted against the deterministic model predicted values $(\mathrm{x})$ and a regression equation was fitted. Hypothesis testing (the slope is not different from unity and regression passes through the origin) was conducted based on the parameters' 95\% confidence intervals. Mean and linear biases of the predictions were assessed by residual analysis as described by St-Pierre (2003). Root mean square error of prediction (RMSEP) was calculated as follows:

RMSEP $=\sqrt{\left[\sum(\text { Observed iNDF }- \text { Predicted iNDF })^{2} / n\right]}$.
Concentrations of iNDF in the feeds determined from the 288-h ruminal in situ incubations in cows consuming diets supplemented with the low level of concentrate were used as the observed values. These values were obtained by statistically correcting for fixed effects of cow within period and feed using the GLM procedures in SAS (release 9.2, 2002-2003; SAS Institute Inc.).

\section{RESULTS}

\section{Diets and Chemical Composition of Feed Samples}

The formulated ingredient composition and actual chemical composition of the 3 different dietary treatments used during the in situ incubations are given in Table 1. Diet composition was primarily varied by changing the source of concentrate supplementation, and proportions varied from 190 (low) to 421 (medium) and 625 (high) $\mathrm{g} / \mathrm{kg}$ of diet DM. Table 2 shows the chemical composition of the forage and concentrate feeds used during the ruminal in situ incubations. All feeds displayed a chemical composition within expected ranges. Considerable variation was present in the material across feed samples; $\mathrm{CP}$ and NDF ranged from 21 to $496 \mathrm{~g}$ and from 237 to $846 \mathrm{~g} / \mathrm{kg}$ of DM, respectively.

\section{Rumen Fluid Data}

Rumen fluid data for the different diets are presented in Table 3. Ruminal concentrations of $\mathrm{NH}_{3}$ and total VFA were affected by diet composition $(P \leq 0.03$ Table 3). Diet composition had no effect on individual VFA, and diets did not differ in terms of the measured rumen $\mathrm{pH}(P \geq 0.07$; Table 3$)$.

Table 1. Ingredient and chemical composition of the different diets ${ }^{1}$ fed to lactating and dry cows during the ruminal in situ incubations

\begin{tabular}{lccc}
\hline Item & Low & Medium & High \\
\hline Ingredient composition $(\mathrm{g} / \mathrm{kg}$ of $\mathrm{DM})$ & & & \\
Grass silage & 810 & 580 & 374 \\
Crimped barley & - & 126 & 225 \\
ExPro $^{2}$ & - & 126 & 150 \\
Solid $220^{3}$ & 190 & 169 & 250 \\
Chemical composition & 381 & 477 & 589 \\
DM (g/kg) & 921 & 937 & 930 \\
OM (g/kg of DM) & 501 & 467 & 400 \\
NDF (g/kg of DM) & 147 & 175 & 185 \\
CP (g/kg of DM) & & \\
\hline
\end{tabular}

${ }^{1}$ Diet composition was primarily varied by changing the proportion of concentrate. Tested concentrate levels were a low of 190, a medium of 421 , and a high of $625 \mathrm{~g} / \mathrm{kg}$ of diet DM.

${ }^{2}$ ExPro is a heat-treated canola meal produced by Lantmännen Lantbruk AB (Stockholm, Sweden).

${ }^{3}$ Solid 220 is a commercial concentrate produced by Lantmännen Lantbruk AB. 
Table 2. Chemical composition of the different feed samples used in the ruminal in situ incubations

\begin{tabular}{|c|c|c|c|c|c|c|c|}
\hline Feed sample ${ }^{1}$ & $\begin{array}{c}\mathrm{DM} \\
(\mathrm{g} / \mathrm{kg})\end{array}$ & $\begin{array}{l}\mathrm{OM}(\mathrm{g} / \mathrm{kg} \\
\text { of DM) }\end{array}$ & $\begin{array}{l}\mathrm{CP}(\mathrm{g} / \mathrm{kg} \\
\text { of DM) }\end{array}$ & $\begin{array}{l}\mathrm{NDF}(\mathrm{g} / \mathrm{kg} \\
\text { of DM) }\end{array}$ & $\begin{array}{l}\mathrm{ADL}(\mathrm{g} / \mathrm{kg} \\
\text { of } \mathrm{DM})\end{array}$ & $\begin{array}{c}\text { iNDF }^{2} \\
\text { (g/kg of DM) }\end{array}$ & $\begin{array}{c}\text { NDICP }^{3} \\
(\mathrm{~g} / \mathrm{kg} \text { of } \mathrm{DM})\end{array}$ \\
\hline Soybean meal & 854 & 925 & 496 & 237 & 4 & 6 & 33 \\
\hline Canola meal & 888 & 914 & 346 & 304 & 91 & 100 & 63 \\
\hline Hempseed cake & 905 & 930 & 341 & 434 & 147 & 409 & 43 \\
\hline Sugar beet pulp & 910 & 925 & 101 & 317 & 12 & 23 & 44 \\
\hline Barley & 887 & 973 & 121 & 249 & 33 & 69 & 30 \\
\hline Barley hulls & 910 & 949 & 21 & 846 & 71 & 333 & 7 \\
\hline Grass silage early & 217 & 932 & 178 & 496 & 40 & 60 & 45 \\
\hline Grass silage late & 266 & 928 & 130 & 611 & 45 & 122 & 32 \\
\hline Corn silage & 304 & 945 & 92 & 405 & 35 & 129 & 9 \\
\hline Barley silage & 377 & 932 & 94 & 510 & 43 & 168 & 7 \\
\hline Grass hay & 864 & 948 & 65 & 574 & 53 & 174 & 22 \\
\hline
\end{tabular}

${ }^{1}$ Early- and late-cut grass silage were harvested on June 12 and 26, 2008, respectively.

${ }^{2} \mathrm{iNDF}=$ indigestible NDF. The SE of the LSM estimates was $1.7 \mathrm{~g} / \mathrm{kg}$ of DM.

${ }^{3} \mathrm{NDICP}=$ neutral detergent insoluble $\mathrm{N} \times 6.25 \mathrm{in} \mathrm{g} / \mathrm{kg}$ of $\mathrm{DM}$.

\section{Effect of Diet Composition and Incubation Time on iNDF}

Across all feed samples, the concentration of iNDF ranged from 6 to $516 \mathrm{~g} / \mathrm{kg}$ of DM (Table 2). The standard error of the least squares means estimates was 1.7 $\mathrm{g} / \mathrm{kg}$ of DM. Feed iNDF concentration was not affected by the cow in which the incubation was conducted $(P$ $=0.14)$. The effect of diet on feed iNDF concentration was significant $(P<0.01)$. The iNDF concentrations across all feeds for the low, medium, and high concentrate diets were 178,186 , and $197 \mathrm{~g} / \mathrm{kg}$ of DM. The effect of incubation time on feed iNDF concentration was significant $(P<0.01)$. The iNDF concentrations across all feeds were 199, 185, and $177 \mathrm{~g} / \mathrm{kg}$ of DM for incubation times of 144, 216, and $288 \mathrm{~h}$, respectively. We also observed significant $(P<0.01)$ interactions between incubation time and diet (Figure 1), incubation time and feed (Figure 2), and diet and feed (Figure
3). The differences of the determined concentrations of iNDF across feeds were greatest between the different incubation times when cows were supplemented with a high proportion of concentrate and decreased with lower proportions of concentrate in the diet, but all were significantly different $(P<0.01)$ within diet (Figure 1). The incubation time had no effect $(P \geq$ 0.11 ) on the measured iNDF concentrations for protein feed samples, but the effect of incubation time generally became more pronounced $(P \leq 0.03)$ as the iNDF concentration in the concentrate ingredients and forage increased (Figure 2). The greatest incubation time-dependent differences in measured iNDF concentration occurred for barley hulls and straw between 144 and $288 \mathrm{~h}$ of incubation (64 and $60 \mathrm{~g} / \mathrm{kg}$ of DM, respectively; $P \leq 0.01)$. The effects of diet composition on iNDF concentrations measured in experimental feed samples were consistent with those presented above, but additionally did differ significantly $(P \leq 0.02)$

Table 3. Effect of diet composition on rumen metabolites and $\mathrm{pH}^{1}$

\begin{tabular}{lccccc}
\hline Item & Low & Medium & High & SE & $P$-value \\
\hline Ammonia $(\mathrm{m} M)$ & 5.3 & 4.1 & 6.0 & 0.31 & 0.03 \\
Total VFA $(\mathrm{mM})$ & 62 & 79 & 100 & 3.3 & $<0.01$ \\
Individual VFA (mol/100 mol) & & & & & \\
Acetate (A) & 74.8 & 72.6 & 66.6 & 1.59 & 0.07 \\
Propionate (P) & 16.8 & 16.9 & 22.4 & 1.73 & 0.16 \\
Butyrate & 8.5 & 10.6 & 11.0 & 0.90 & 0.39 \\
A:P & 4.5 & 4.4 & 3.1 & 0.40 & 0.13 \\
pH & 6.97 & 6.68 & 6.50 & 0.090 & 0.12 \\
\hline
\end{tabular}

${ }^{1}$ Diet composition was primarily varied by changing the proportion of concentrate. Tested concentrate levels were a low of 190, a medium of 421, and a high of $625 \mathrm{~g} / \mathrm{kg}$ of diet DM.

${ }^{2}$ Probability of a significant effect of diet composition. 


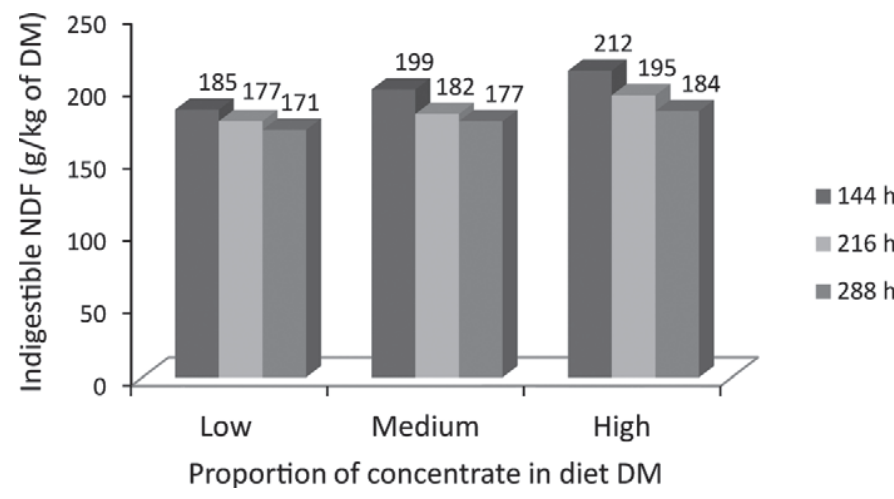

Figure 1. The effect of varying the incubation time on the concentration of indigestible NDF (iNDF) across all experimental feeds incubated in dairy cows consuming a low of maximum 190, a medium of 421, and a high of 625 level of concentrate in grams per kilogram of diet DM. Each bar in the figure is labeled with the actual iNDF concentration for the corresponding feed. The SE of the presented LSM estimates was $1.2 \mathrm{~g} / \mathrm{kg}$ of DM.

between diet compositions for palm kernel cake, dried alfalfa, and birch twigs (Figure 3). The concentration of iNDF in canola meal was significantly different between medium and low concentrate diets $(P<0.01$; Figure $3)$. The greatest differences between the high and low concentrate diets in measured iNDF concentrations occurred for barley hulls and straw (67 and $58 \mathrm{~g} / \mathrm{kg}$ of DM, respectively; $P \leq 0.01$ ).

\section{Evaluation of Prediction Models of Unavailable NDF}

Unavailable NDF predicted according to the NRC model (NRC, 2001) and CNCPS (Fox et al., 2004) averaged 173 and $177 \mathrm{~g} / \mathrm{kg}$ of $\mathrm{DM}$, and ranged from 18 to 486 and from 10 to $733 \mathrm{~g} / \mathrm{kg}$ of DM, respectively, across all feed samples in this study. A linear regression analysis and RMSEP for the predictive models are presented in Figure 4. The slope and intercept of the fitted line for the plot of the predicted values against the experimental observations were not different from unity and zero, respectively $(P>0.05)$, for the NRC (2001) model. The slope for the CNCPS predictions differed from unity $(P \leq 0.05)$, but the intercept was not distinguishable from zero $(P>0.05)$. If the birch twigs data were excluded in the CNCPS predictions of unavailable NDF, neither slope nor intercept differed from unity or zero, respectively $(P>0.05)$ in the regression of observed versus model-predicted $[\mathrm{y}=$ $0.94( \pm 0.187) \mathrm{x}+16( \pm 31.7)]$, and RMSEP decreased to $64.9 \mathrm{~g} / \mathrm{kg}$ of DM. Likewise, we observed no linear relationships between residuals and centered predicted values (or systematic errors) for the CNCPS prediction model when excluding birch twigs. Neither mean nor slope biases were detected for the NRC (2001) predic- tions of unavailable NDF over all samples (results not presented).

\section{DISCUSSION}

\section{Methodological Aspects}

Accurate information on the iNDF concentration of a feed is essential when estimating the kinetic parameters, which are often calculated without accounting for the indigestible residue or by using iNDF values determined over a too-short fermentation time (Mertens, 1993). Increasing the in situ incubation time from 96 to $288 \mathrm{~h}$ clearly reduced the measured iNDF concentration for grass silages of different maturities, and the reductions became more pronounced as forage quality decreased (Rinne et al., 1997, 2002). Further, the asymptotic values estimated from a nonlinear model of 96-h in situ disappearance data did not give precise predictions of iNDF compared with the results of the 288-h ruminal in situ incubation (Rinne et al., 1997, 2002). Moreover, Koukolová et al. (2004) observed that measurements of potentially digestible NDF (pdNDF) in grass and clover forages based on ruminal in situ incubation times of up to $168 \mathrm{~h}$ were substantially lower than those obtained from $504 \mathrm{~h}$ of incubation. Further, they observed that pdNDF determined at the 504-h incubation time was higher than that of the asymptote predicted from the other time points. It was suggested that this may occur because the rate of digestion decreases over extended incubations. Mertens (2005) recommended that the asymptote can only be accurately estimated when digestion is $>99 \%$ complete, which is rarely the case for in situ incubation of $96 \mathrm{~h}$ or less. Digestion of NDF continues even after long incubation periods in situ (Robinson et al., 1986), suggesting that extended incubations are required to precisely estimate the iNDF concentration of a feed. The present study suggests that an incubation time of at least $288 \mathrm{~h}$ is needed for complete digestion in situ when bags of small pore size are used. In agreement with the in situ data, Van Soest et al. (2005) demonstrated, from re-inoculated in vitro incubations up to $240 \mathrm{~h}$, that forages have a fast- and a slow-digesting fiber pool, with digestion rates of the latter ranging from 0.4 to $1.2 \% / \mathrm{h}$.

The accuracy of iNDF values can be evaluated using in vivo pdNDF digestibility data. The average pdNDF digestibility for 86 different forages in sheep fed at maintenance was 0.85 (Huhtanen et al., 2006), whereas that for 33 legume silages was 0.88 (Rinne et al., 2006). Assuming a residence time of $50 \mathrm{~h}$ in the rumen and selective retention of feed particles, the mean first-order rates of pdNDF digestion according to these 2 studies would be 6.4 and $7.5 \% / \mathrm{h}$, respectively. In conjunction 


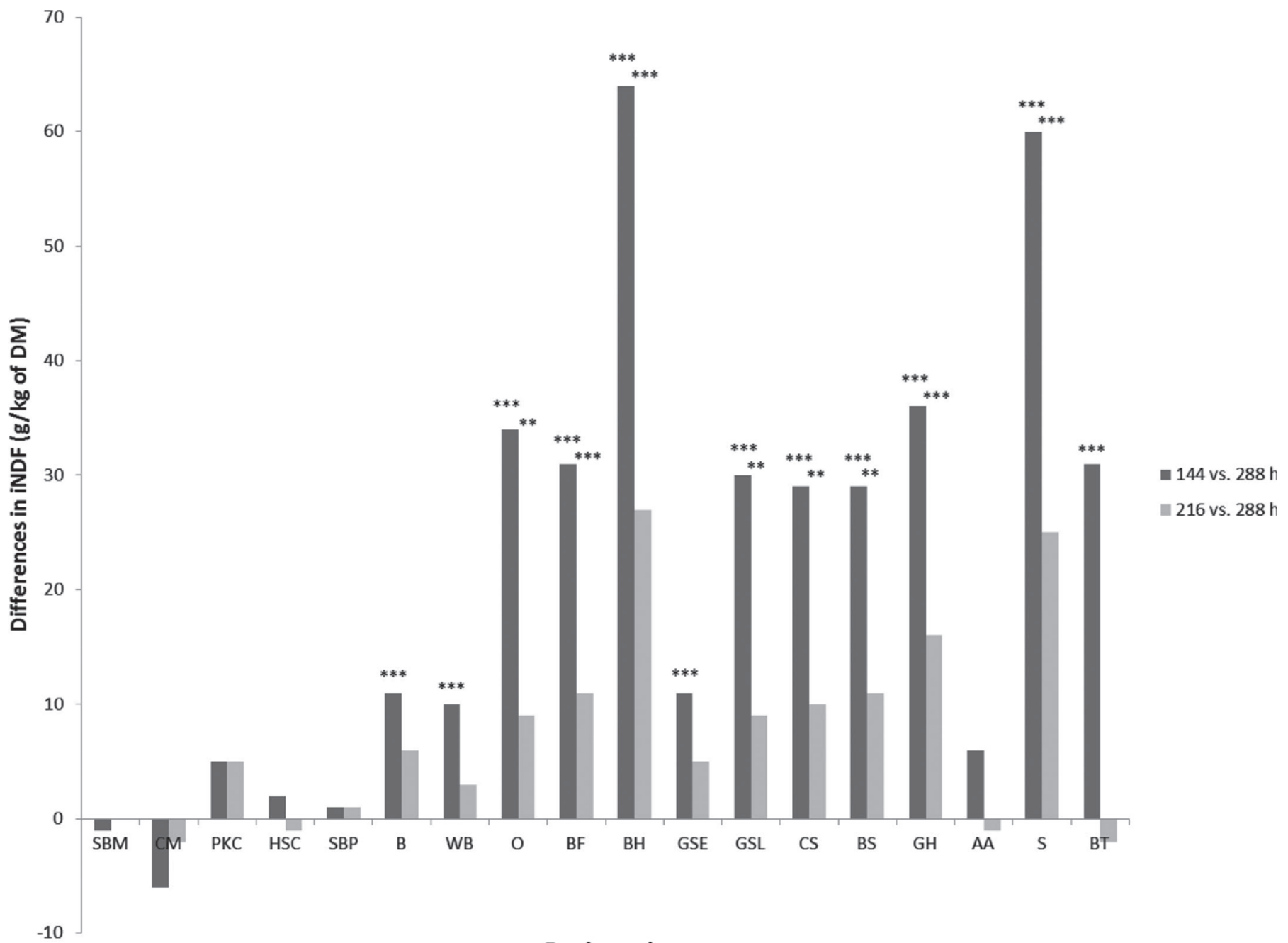

Feed sample

Figure 2. The effect of varying the incubation time on the concentration of indigestible NDF (iNDF) in the individual experimental feeds expressed as the difference between the indicated value and that obtained following a 288-h incubation. $\mathrm{SBM}=\mathrm{soybean}$ meal, $\mathrm{CM}=$ canola meal, $\mathrm{PKC}=$ palm kernel cake, HSC = hempseed cake, $\mathrm{SBP}=$ sugar beet pulp, $\mathrm{B}=$ barley, $\mathrm{WB}=$ wheat bran, $\mathrm{O}=\mathrm{oat}, \mathrm{BF}=\mathrm{barley}$ fiber, $\mathrm{BH}$ = barley hulls, GSE = early-cut grass silage, GSL = late-cut grass silage, $\mathrm{CS}=$ corn silage, $\mathrm{BS}=$ barley silage, GH $=$ grass hay, AA $=$ dried alfalfa, $\mathrm{S}=$ barley straw, and BT = birch twigs. The SE of the presented LSM estimates was $2.9 \mathrm{~g} / \mathrm{kg}$ of DM. Asterisks indicate the level of the least significant difference: ${ }^{* * *} P \leq 0.01$ and ${ }^{* *} P \leq 0.05$.

with accurate empirical predictions of in vivo OM digestibility (Huhtanen et al., 2006; Krizsan et al., 2012b), these figures suggest that measurements of forage iNDF concentration based on long in situ incubations using bags with small pore size give more biologically correct estimates of the cell wall fraction that is unavailable for microbial digestion in ruminants.

\section{Effects of Diet Composition and Incubation Time on iNDF}

The intrinsic rate and extent of cell wall digestion set the upper limit for the utilization of forages by ruminants. It has been demonstrated that extrinsic fac- tors such as dietary supplements or rapidly digestible carbohydrates reduce the intrinsic rates of plant cell wall digestion. Reductions in rate of NDF digestion estimated by rumen evacuation have been reported by Khalili and Huhtanen (1991) for sucrose supplements, by Stensig et al. (1998) for sucrose and starch, and by Oba and Allen (2003) for dietary starch supplementation. Reduced rates of in situ NDF digestion following increased concentrate supplementation have commonly been reported [see reviews by Nocek (1988) and Weiss (1994)]. Although the evidence suggests that reductions in the capacity for cell wall digestion in ruminants are associated with reduced rumen $\mathrm{pH}$ values, little evidence exists that this is the sole causative factor (Mertens, 


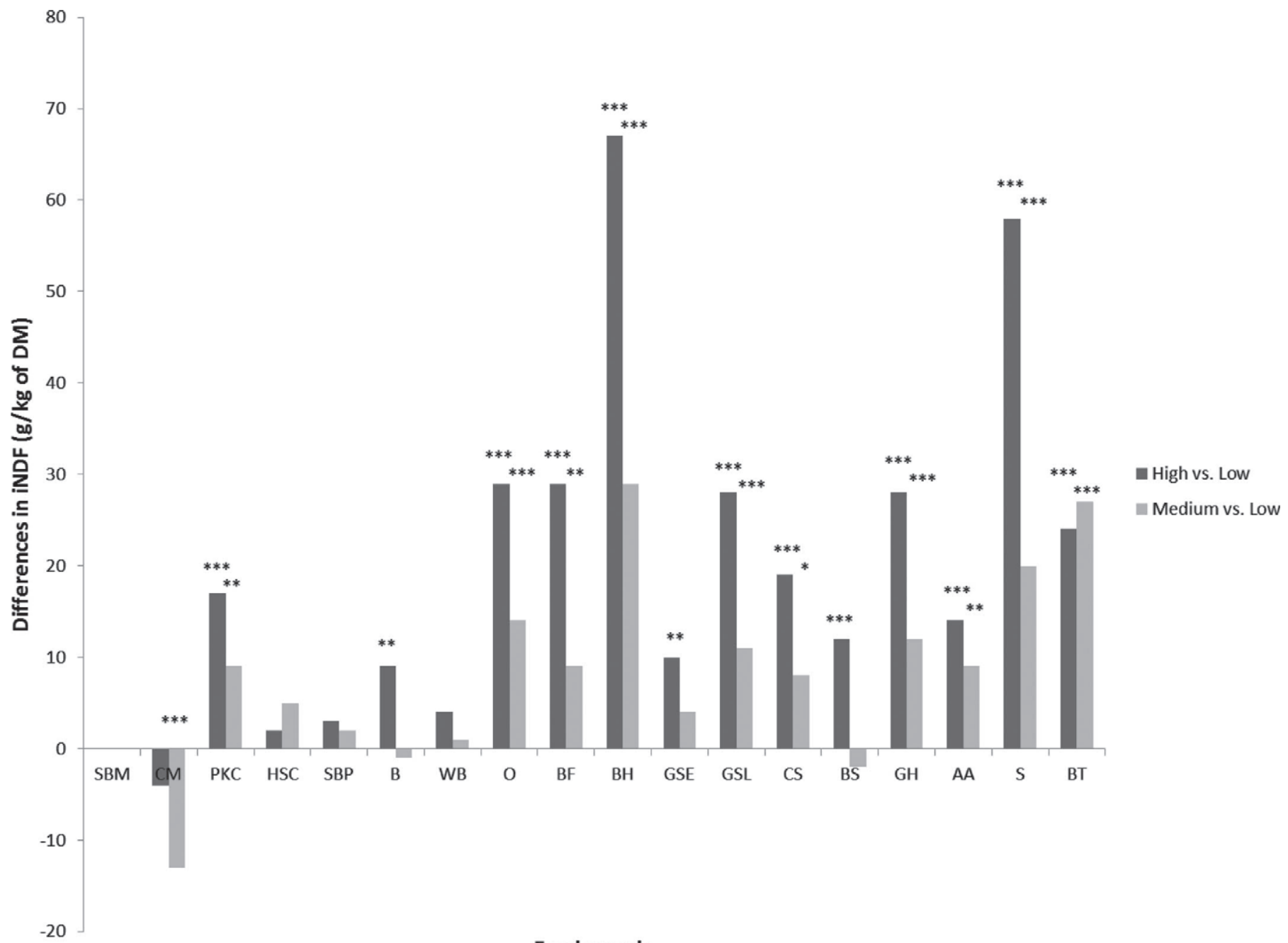

Feed sample

Figure 3. The effect of varying the proportion of supplemental concentrate in the diet on the indigestible NDF (iNDF) concentration in the individual experimental feeds, expressed as the difference between the indicated value and that for the diet with the lowest level of supplementation. The cannulated dairy cows were fed diets supplemented with a low of 190, a medium of 421, and a high of 625 level of concentrate in grams per kilogram of diet DM. SBM = soybean meal, $\mathrm{CM}=$ canola meal, $\mathrm{PKC}=$ palm kernel cake, $\mathrm{HSC}=$ hempseed cake, $\mathrm{SBP}=$ sugar beet pulp, $\mathrm{B}=$ barley, $\mathrm{WB}=$ wheat bran, $\mathrm{O}=$ oat, $\mathrm{BF}=$ barley fiber, $\mathrm{BH}=$ barley hulls, $\mathrm{GSE}=$ early-cut grass silage, GSL $=$ late-cut grass silage, $\mathrm{CS}$ $=$ corn silage, $\mathrm{BS}=$ barley silage, $\mathrm{GH}=$ grass hay, $\mathrm{AA}=$ dried alfalfa, $\mathrm{S}=$ barley straw, and $\mathrm{BT}=$ birch twigs. The $\mathrm{SE}$ of the LSM was $2.9 \mathrm{~g} /$ $\mathrm{kg}$ of DM. Asterisks indicate the level of the least significant difference: ${ }^{* * *} P \leq 0.01,{ }^{* *} P \leq 0.05$, and ${ }^{*} P \leq 0.10$.

1993). Mould et al. (1983) differentiated the adverse effects of nonstructural carbohydrates on cell wall digestion between a "pH effect" and a "carbohydrate effect." Studies using continuous cultures that allowed for independent adjustment of the $\mathrm{pH}$ and level of rapidly degradable carbohydrates showed that the level of carbohydrates affected fiber digestibility more than did $\mathrm{pH}$ (Weisbjerg et al., 1999). The small differences in rumen $\mathrm{pH}$ observed in this work do not support the hypothesis that changes in rumen $\mathrm{pH}$ are the main cause of the reduced cellulolytic activity observed when feeds are incubated in cows fed diets supplemented with large amounts of concentrate.
The effects of extrinsic diet and animal characteristics on the potential extent of NDF digestion or iNDF concentration have not been studied using prolonged ( $>96$ h) incubation periods. Lindberg (1981) and Huhtanen and Jaakkola (1994) reported reductions in the extent of NDF digestion in forages when the proportion of concentrate in the diet was increased from 0 to $700 \mathrm{~g} / \mathrm{kg}$ diet DM or from 250 to $750 \mathrm{~g} / \mathrm{kg}$ diet DM, respectively. In these studies, the potential extent of NDF digestion was estimated using nonlinear models by identifying the asymptote of the NDF disappearance curves. The adverse effects of nonstructural carbohydrates on the potential extent of in situ NDF digestion were greater 

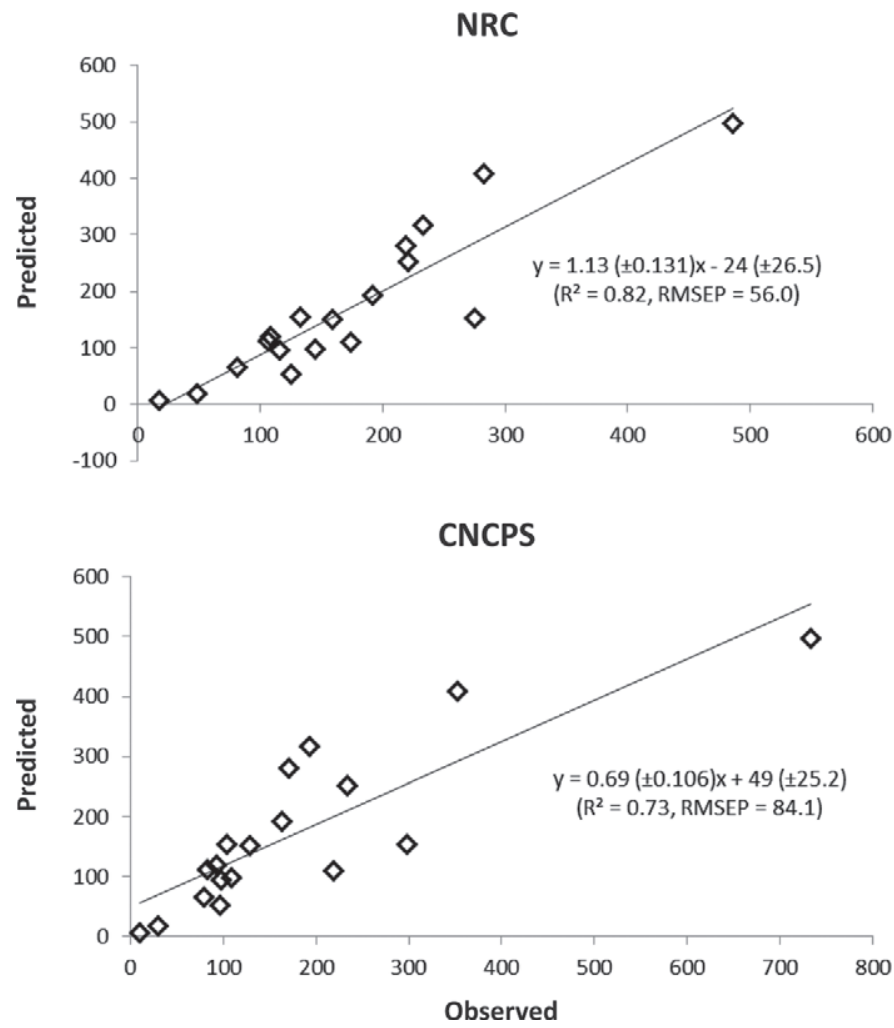

Figure 4. Relationships between predicted [NRC (2001) and Cornell Net Carbohydrate and Protein System (CNCPS; Fox et al., 2004)] and observed concentrations of indigestible NDF in experimental feeds. The coefficient of determination $\left(\mathrm{R}^{2}\right)$ and root mean square error of prediction (RMSEP) are given for both regressions.

for less-digestible forages than for highly digestible ones (Mould et al., 1983; Huhtanen and Jaakkola, 1994). As discussed in the review by Bannink and Tamminga (2005), the observation that ruminal NDF digestibility decreases as starch intake increases is also consistent with the in situ data. These results are in agreement with generally larger differences in measured concentrations of iNDF with decreased incubation time, and with a larger proportion of concentrate in the diets for concentrate feed and forages with less pdNDF in the DM. However, if the pdNDF concentration of the feed is very low, the effects of incubation time and diet composition are expected to be small. This was seen for hempseed cake, but not for birch twigs, despite both feeds being low in pdNDF. Birch twigs contained much more ADL than hempseed cake, which probably affected the fibrolytic capacity of the particle-associated microbial population (Krause et al., 2003).

We observed no time effect, but did find a small effect of diet composition on the concentration of iNDF in incubated protein feeds. Palm kernel cake is regarded as a medium-grade protein feed that is high in fiber. However, the finding that the iNDF concentration for canola meal was lower in cows consuming a diet with a medium level of concentrate compared with those consuming either high or low concentrate diets is not consistent with the other results and remains unexplained.

Alfalfa was less affected by diet composition or incubation time than were grass silages and grass hay in this study. Grant and Mertens (1992) reported that the effects of rumen $\mathrm{pH}$ and starch addition on in vitro cell wall digestion varied with substrate. The digestion of alfalfa was less sensitive to lower rumen $\mathrm{pH}$ and starch addition than that of brome grass hay. Huhtanen et al. (2006) suggested that the reduced effect of diet composition on legume digestion relative to grasses may indicate that the fibers of the former are more rapidly digested. This is probably also the reason why protein feeds were not affected more by diet and time effects in this study.

Increasing the incubation time did not compensate for the reduced digestion rate due to increased supplementation of nonstructural carbohydrates in this study. The present results showed that after the 288 -h in situ incubation, feeding high concentrate diets increased iNDF concentration, suggesting that even the prolonged incubation time could not compensate for the adverse effects of nonstructural carbohydrates on NDF digestion. There might also be indirect effects of time and dietary interactions on the determined concentration of iNDF. It has been claimed that the microenvironment within the bags during in situ incubations differs from that inside the rumen and that it suppresses microbial activity to some extent (Meyer and Mackie, 1986). The activity of particle-associated enzymes in rumen digesta is higher than that for enzymes associated with feed particles recovered from in situ bags following incubation (Nozière and Michalet-Doreau, 1996; Huhtanen et al., 1998). It remains unclear whether the differences in iNDF concentration could be eliminated by extending the incubation period beyond $288 \mathrm{~h}$. This seems unlikely because the rate of pdNDF digestion was very slow between 144 and $288 \mathrm{~h}(0.9 \pm 0.1 \% / \mathrm{h})$ when calculated under the assumption that complete digestion would be achieved within $288 \mathrm{~h}$ in cows consuming the low concentrate diet. Excluding feeds with negligible dietary effects on iNDF concentration (hempseed cake, canola and soybean meal, barley, sugar beet pulp), it took an average of almost $300 \mathrm{~h}$ of further incubation to achieve an iNDF concentration that was $1 \%$ greater than that observed for a low concentrate diet at $288 \mathrm{~h}$.

\section{Nutritional Uniformity and Applicability}

Acid detergent lignin in forage analyses has passed the Lucas test of nutritive unavailability and does not appear to differ between feedstuffs (Van Soest, 1994; 
Krizsan et al., 2012a). Lignin has generally been regarded as the substance that is primarily responsible for limiting forage digestion. The surface-limiting concept introduced by Conrad et al. (1984) is based on the idea that lignin as measured by ADL imposes a similar constraint on NDF digestibility, irrespective of lignin type, plant species, or growth environment. Van Soest et al. (2005) verified the close linear relationship between lignin and iNDF for various forages. The CNCPS prediction model (Fox et al., 2004) assumes a constant effect of lignin on the maximum extent of digestion across all forages, whereas the NRC (2001) prediction model predicts a decreasing effect on NDF digestion with increased lignin concentration. In the NRC (2001) model, lignin affects the estimated NDF, in that carbohydrates encrusted by lignin are discounted. Further, NDF is adjusted for the NDF-bound nitrogen content by subtracting NDICP from NDF in the equation according to Weiss et al. (1992).

No systematic errors were revealed in the evaluation of the predictive performance of the NRC and CNCPS models in this study. However, none of the models were very precise. The surface area model predicted unavailable NDF concentration slightly better than the linear model when their output was compared with experimental data from 288 -h in situ incubations in cows consuming low amounts of concentrate. Calculating the effect of the RMSEP on feed OM digestibility according to Huhtanen et al. (2006) yielded prediction errors of 74 and $111 \mathrm{~g} / \mathrm{kg}$ for the NRC and CNCPS prediction models, respectively. Despite the biological relevance of using lignin in predictions of iNDF, it has not been successful across years and forage types (Huhtanen et al., 2006; Krämer et al., 2010). Although, overall, the slope was 2.4 between permanganate lignin and iNDF in the study by Huhtanen et al. (2006), the slopes for individual forage species (primary and regrowth grasses, red clover, and whole-crop cereals) varied between 2.8 and 5.5. Krämer et al. (2010) observed an even greater range (from 0.3 to 4.7 ) for the relationship between iNDF and ADL when concentrates and byproducts were evaluated alongside different types of forages. In addition to variation between forage types, lignin accumulation can be affected by annual growth conditions. This was demonstrated by Nousiainen et al. (2003), who included an effect of year in the predictions of OM digestibility in grass silages and thereby decreased the prediction error markedly. Lignin was also strongly correlated with NDF across a wider forage population when year was included in the statistical analysis, indicating that environmental differences between years affect lignification of forage cell walls (Huhtanen et al., 2006). In a recent study with tropical forages (Gomes et al., 2011), lignin analyzed by several methods was significantly correlated with iNDF concentration, but the resulting prediction errors were relatively high $(58.7-87.3 \mathrm{~g} / \mathrm{kg}$ of NDF). This may reflect relatively high errors in the determinations of both iNDF and lignin, despite correcting for protein contamination of the latter.

Indigestible NDF has been applied in calibrations of NIRS for routine determinations of forage fiber quality in the Nordic countries. Standardization of the reference method is essential for the development of calibrations with low prediction errors. Krizsan et al. (2012b) emphasized the strong influence of random variation in the reference methods used when calibrating NIRS on the total prediction error. Most in situ studies have indicated that random variation decreases as the length of the incubation period increases (Mertens, 2005). This is because some of the forage NDF is indigestible. Increased incubation time decreases the size of the pdNDF fraction in the forage, reducing the variation in the quantity of residual material relative to the original sample size. In the data set of Huhtanen and Krizsan (2011), the standard deviation of replicate samples was $5 \mathrm{~g} / \mathrm{kg}$ of DM for iNDF, which was much lower than those for in vitro methods based on the use of buffered rumen fluid. In addition, performing one long-term incubation is less labor intensive than collecting time series for in vitro or in situ incubations.

\section{CONCLUSIONS}

Although lignin plays a role in cell wall degradation and is therefore strongly correlated with iNDF concentrations, measured lignin concentrations of feeds and forages are not universally useful for estimating iNDF concentrations or potential NDF digestibility across a wide range of feeds. Indigestible NDF should be determined based on 288-h ruminal in situ incubations in cows consuming diets containing a low proportion of concentrate to represent the feed fraction that is unavailable to the animal. The determination of forage iNDF concentration by long in situ incubation using bags with a small pore size has resulted in more biologically correct estimates of the cell wall fraction that is unavailable for microbial digestion in ruminants. Further, the method separates NDF into iNDF and pdNDF, which is useful in empirical models and required in mechanistic models for predicting NDF digestibility. Further development of mechanistic models will be required to properly account for the effects of diet composition on iNDF concentrations.

\section{ACKNOWLEDGMENTS}

The authors thank Evelina Viklund and the barn crew for feeding and caring for the animals at Röbäcks- 
dalen Research Farm (Umeå, Sweden), Lars Wallgren (SLU Umeå, Sweden) for assisting with the bags, and Ann-Sofi Hahlin (SLU Umeå, Sweden) for laboratory analyses.

\section{REFERENCES}

Ahvenjärvi, S., A. Vanhatalo, P. Huhtanen, and T. Varvikko. 2000. Determination of reticulo-rumen and whole-stomach digestion in lactating cows by omasal canal or duodenal sampling. Br. J. Nutr. 83:67-77.

AOAC International. 1998. Official Methods of Analysis. 16th ed., 4th rev. AOAC International, Gaithersburg, MD.

Bannink, A., and S. Tamminga. 2005. Rumen function. Pages 263-288 in Quantitative Aspects of Ruminant Digestion and Metabolism. 2nd ed. J. Dijkstra, J. M. Forbes, and J. France, ed. CAB International, Wallingford, UK.

Broderick, G. A., and J. H. Kang. 1980. Automated simultaneous determination of ammonia and total amino acids in ruminal fluid and in vitro media. J. Dairy Sci. 63:64-75.

Conrad, H. R., W. P. Weiss, W. O. Odwongo, and W. L. Shockey. 1984. Estimating net energy lactation from components of cell solubles and cell walls. J. Dairy Sci. 67:427-436.

Danfær, A., P. Huhtanen, P. Udén, J. Sveinbjörnsson, and H. Volden. 2006. The Nordic dairy cow model, Karoline-Description. Pages 383-406 in Nutrient Digestion and Utilization in Farm Animals: Modelling Approaches. E. Kebreab, J. Dijkstra, A. Bannink, J. Gerrits, and J. France, ed. CAB International, Wallingford, UK.

Ericson, B., and J. André. 2010. HPLC-Applications for agricultural and animal science. Pages 23-26 in Proc. 1st Nordic Feed Science Conf., Uppsala, Sweden. SLU Repro, Uppsala, Sweden.

Fox, D. G., L. O. Tedeschi, T. P. Tylutki, J. B. Russell, M. E. Van Amburgh, L. E. Chase, A. N. Pell, and T. R. Overton. 2004. The Cornell Net Carbohydrate and Protein System model for evaluating herd nutrition and nutrient excretion. Anim. Feed Sci. Technol. 112:29-78.

Gomes, D. I., E. Detmann, S. C. Valadares Filho, R. S. Fukushima, M. A. de Souza, T. N. P. Valente, M. F. Paulino, and A. C. de Queiroz. 2011. Evaluation of lignin contents in tropical forages using different analytical methods and their correlations with degradation of insoluble fiber. Anim. Feed Sci. Technol. 168:206-222.

Grant, R. J., and D. R. Mertens. 1992. Influence of buffer $\mathrm{pH}$ and raw corn starch addition on in vitro fiber digestion kinetics. J. Dairy Sci. 75:2762-2768.

Huhtanen, P., and S. Jaakkola. 1994. Influence of grass maturity and diet on ruminal dry matter and neutral detergent fibre digestion kinetics. Arch. Tierernahr. 47:153-167.

Huhtanen, P., K. Kaustell, and S. Jaakkola. 1994. The use of internal markers to predict total digestibility and duodenal flow of nutrients in cattle given six different diets. Anim. Feed Sci. Technol. 48:211-227.

Huhtanen, P., and S. J. Krizsan. 2011. Models to estimate the nutritive value and intake of conserved forages. Pages 197-231 in Proc. II Int. Symp. Forage Quality and Conservation. J. L. P. Daniel, M. Zopollatto, L. G. Nussio, ed. Fundação de Estudos Agrários Luiz de Queiroz, Piracicaba, Sao Paulo, Brazil.

Huhtanen, P., J. Nousiainen, and M. Rinne. 2006. Recent developments in forage evaluation with special reference to practical applications. Agric. Food Sci. 15:293-323.

Huhtanen, P., A. Vanhatalo, and T. Varvikko. 1998. Enzyme activities of rumen particles and feed samples incubated in situ with differing types of cloth. Br. J. Nutr. 79:161-168.

Khalili, H., and P. Huhtanen. 1991. Sucrose supplements in cattle given grass silage based diet. 2. Digestion of cell wall carbohydrates. Anim. Feed Sci. Technol. 33:262-273.

Koukolová, V., M. R. Wisbjerg, T. Hvelplund, P. Lund, and B. Čermák. 2004. Prediction of NDF degradation chracteristics of grass and grass/clover forages based on laboratory methods. J. Anim. Feed Sci. 13:691-708.

Krämer, M., M. R. Weisbjerg, and P. Lund. 2010. Estimation of indigestible NDF in feedstuffs for ruminants. Pages 15-20 in Proc. 1st Nordic Feed Science Conf., Uppsala, Sweden. SLU Repro, Uppsala, Sweden.

Krause, D. O., S. E. Denman, R. I. Mackie, M. Morrison, A. L. Rae, G. T. Attwood, and C. S. McSweeney. 2003. Opportunities to improve fiber degradation in the rumen: Microbiology, ecology, and genomics. FEMS Microbiol. Rev. 27:663-693.

Krizsan, S. J., S. Ahvenjärvi, H. Volden, and G. A. Broderick. 2010. Estimation of rumen outflow in dairy cows fed grass silage-based diets by use of reticular sampling as an alternative to sampling from the omasal canal. J. Dairy Sci. 93:1138-1147.

Krizsan, S. J., H. M. Alamouti, and P. Huhtanen. 2012a. Indigestible NDF in predictions of grass and red clover silage digestibility. J. Dairy Sci. 95(Suppl. 2.):462. (Abstr.)

Krizsan, S. J., L. Nyholm, J. Nousiainen, K.-H. Südekum, and P. Huhtanen. 2012b. Comparison of in vitro and in situ methods in evaluation of forage digestibility in ruminants. J. Anim. Sci. 90:3162-3173. http://dx.doi.org/10.2527/jas.2011-4347.

Lindberg, J. E. 1981. The effect of basal diet on the ruminal degradation of dry matter, nitrogenous compounds and cell walls in nylon bags. Swed. J. Agric. Res. 11:159-169.

Mertens, D. R. 1993. Kinetics of cell wall digestion and passage in ruminants. Pages 535-570 in Forage Cell Wall Structure and Digestibility. H. G. Jung, D. R. Buxton, R. D. Hatfield, and J. Ralph, ed. American Society of Agronomy, Madison, WI.

Mertens, D. R. 2005. Rate and extent of digestion. Pages 13-47 in Quantitative Aspects of Ruminant Digestion and Metabolism. 2nd ed. J. Dijkstra, J. M. Forbes, and J. France, ed. CAB International, Wallingford, UK.

Mertens, D. R., M. Allen, J. Carmany, J. Clegg, A. Davidowicz, M. Drouches, K. Frank, D. Gambin, M. Garkie, B. Gildemeister, D. Jeffress, C. S. Jeon, D. Jones, D. Kaplan, G. N. Kim, S. Kobata, D. Main, X. Moua, B. Paul, J. Robertson, D. Taysom, N. Thiex, J. Williams, and M. Wolf. 2002. Gravimetric determination of amylase-treated neutral detergent fiber in feeds with refluxing in beakers or crucibles: Collaborative study. J. AOAC Int. $85: 1217-1240$

Meyer, J. H., and R. I. Mackie. 1986. Microbiological evaluation of the intraruminal in sacculus digestion technique. Appl. Environ. Microbiol. 51:622-629.

Mould, F. L., E. R. Ørskov, and S. O. Mann. 1983. Associative effects of mixed feed. 1 Effects of type and level of carbohydrate supplementation and the influence of rumen fluid $\mathrm{pH}$ on cellulolysis in vivo and dry matter digestion of various roughage. Anim. Feed Sci. Technol. 10:15-30.

Nocek, J. E. 1988. In situ and other methods to estimate ruminal protein and energy digestibility: A review. J. Dairy Sci. 71:20512069.

Nordic Committee on Food Analysis. 1976. Nitrogen: Determination in Food and Feed according to Kjeldahl. No. 6. 3rd ed. Nordic Committee on Food Analysis, Esbo, Finland.

Nousiainen, J., S. Ahvenjärvi, M. Rinne, M. Hellämäki, and P. Huhtanen. 2004. Prediction of indigestible cell wall fraction of grass silage by near infrared reflectance spectroscopy. Anim. Feed Sci. Technol. 115:295-311.

Nousiainen, J., M. Rinne, M. Hellämäki, and P. Huhtanen. 2003. Prediction of the digestibility of primary growth and regrowth grass silages from chemical composition, pepsin-cellulase solubility and indigestible cell wall content. Anim. Feed Sci. Technol. 110:61-74.

Nozière, P., and B. Michalet-Doreau. 1996. Validation of in sacco method. Influence of sampling site, nylon bag or rumen contents, on fibrolytic activity of solid-associated microorganisms. Anim. Feed Sci. Technol. 57:203-210.

NRC. 2001. Nutrient Requirements of Dairy Cattle. 7th rev. ed. Natl. Acad. Press, Washington, DC. 
Oba, M., and M. S. Allen. 2003. Effects of corn grain conservation method on ruminal digestion kinetics for lactating dairy cows at two dietary starch concentrations. J. Dairy Sci. 86:184-194.

Raffrenato, E., and M. E. Van Amburgh. 2011. Technical note: Improved methodology for analyses of acid detergent fiber and acid detergent lignin. J. Dairy Sci. 94:3613-3617.

Rinne, M., P. Huhtanen, and S. Jaakkola. 1997. Grass maturity effects on cattle fed silage-based diets. 2. Cell wall digestibility, digestion and passage kinetics. Anim. Feed Sci. Technol. 67:19-35.

Rinne, M., P. Huhtanen, and S. Jaakkola. 2002. Digestive processes of dairy cows fed silages harvested at four stages of maturity. J. Anim. Sci. 80:1986-1998.

Rinne, M., A. Olt, J. Nousiainen, A. Seppälä, M. Tuori, C. Paul, M D. Fraser, and P. Huhtanen. 2006. Prediction of legume silage digestibility from various laboratory methods. Grass Forage Sci. 61:354-362.

Robinson, P. J., J. G. Fadel, and S. Tamminga. 1986. Evaluation of mathematical models to describe neutral detergent residue in terms of its susceptibility to degradation in the rumen. Anim. Feed Sci. Technol. 15:249-271.

St-Pierre, N. R. 2003. Reassessment of biases in predicted nitrogen flows to the duodenum by NRC 2001. J. Dairy Sci. 86:344-350.

Stensig, T., M. R. Weisbjerg, and T. Hvelplund. 1998. Digestion and passage kinetics of fibre in dairy cows as affected by the proportion of wheat starch or sucrose in the diet. Acta Agric. Scand. Anim. Sci. 48:129-140.

Van Soest, P. J. 1994. Nutritional Ecology of the Ruminant. 2nd ed. Cornell Univ. Press, Ithaca, NY.

Van Soest, P. J., M. E. Van Amburgh, J. B. Robertson, and W. F. Knaus. 2005. Validation of the 2.4 times lignin factor for ultimate extent of NDF digestion, and curve peeling rate of fermentation curves into pools. Pages 139-149 in Proc. Cornell Nutrition Conf. for Feed Manufacturers, East Syracuse, NY. Cornell University, Ithaca, NY.

Weisbjerg, M. R., H. Gado, T. Hvelplund, and B. B. Jensen. 1999. The effect of easily fermentable carbohydrates and $\mathrm{pH}$ on fibre digestibility and VFA pattern in an in vitro continuous culture system. S. Afr. J. Anim. Sci. 29:112-113.

Weiss, W. P. 1994. Estimation of digestibility of forages by laboratory methods. Pages 644-681 in Forage Quality, Evaluation and Utilization. G. C. Fahey, ed. American Society of Agronomy Inc., Crop Science Society of America Inc., Soil Science Society of America Inc., Madison, WI.

Weiss, W. P., H. R. Conrad, and N. R. St. Pierre. 1992. A theoretically-based model for predicting total digestible nutrient values of forages and concentrates. Anim. Feed Sci. Technol. 39:95-110. 